\title{
Escritura y praxis documental para la gestión de enfermos en la hospitalidad hispalense (siglos XV-XVIII)
}

\section{Writing and documentary praxis for the management of patients in Seville hospitality (XV-XVIII centuries)}

\author{
PABLO ALBERTO MESTRE NAVAS \\ Universidad de Sevilla \\ mestre@us.es
}

\begin{abstract}
Resumen: La proliferación de hospitales en la Sevilla de la Edad Moderna mejoró la red asistencial existente en la ciudad. Los establecimientos creados, a iniciativa particular o por instituciones públicas, se especializaron en la atención de colectivos sociales concretos y en diferentes enfermedades, estipulándose variados procedimientos de ingreso y atención al paciente, que se vertebraron en los estatutos y constituciones que marcaron las pautas del circuito sanitario dentro del establecimiento. El diagnóstico y la prescripción constituyeron las dos actividades principales de la atención sanitaria, que se materializó a través del ingreso y la visita médica. Fruto de ellas, los hospitales crearon instrumentos documentales y librarios para ejercer el control y la gestión de los dolientes durante la Edad Moderna.
\end{abstract}

A través de las fuentes documentales y bibliográficas consultadas, este artículo trata de identificar los diferentes procesos de ingreso, así como las características de la visita médica y la participación de diferentes actores en la atención de los enfermos en la Sevilla de esta época, señalando los elementos definitorios de los libros y documentos que oficiales, sacerdotes, médicos o boticarios crearon para ejercer ese control efectivo de los pacientes.

Palabras clave: Registros de enfermos, libros de botica, ingresos, visita médica, hospitales de Sevilla.

Abstract: The proliferation of hospitals in the city of Seville throughout the Modern Age improved the existing health care network. The newly created establishments, be it by private initiative or by public institutions, specialized in the care of specific social groups and in different diseases. They stipulated diverse admission procedures and patient care that were captured in the statutes and constitutions, marking the guidelines of the sanitary circuit within the establishment. Diagnosis and prescription marked the two milestones of the health activity that materialized through the admission and the medical visit. As a

Recibido: 23 de julio de 2018; aceptado: 6 de marzo de 2019; publicado: 30 de septiembre de 2019. Revista Historia Autónoma, 15 (2019), pp. 29-50 e-ISSN: 2254-8726; DOI: https://doi.org/10.15366/rha2019.15.002 
result, hospitals created documentary and librarian instruments in order to control and manage the mourners during the Modern Age.

Through the analysis of documentary and bibliographic sources, this article attempts to identify the different admission processes, as well as the characteristics of the medical visit and the participation of different actors in the care of the patients in Modern Age Seville, pointing out the defining elements of the books and documents that officials, priests, doctors or apothecaries created to exercise an effective control over patients.

Keywords: Patient records, pharmacy books, admission, medical visit, hospitals of Seville.

\section{La hospitalidad sevillana en el Antiguo Régimen}

Desde el siglo XIII ${ }^{1}$, la capital andaluza asistió a las primeras fundaciones hospitalarias que nacieron para erradicar los incipientes problemas de salud que experimentaron los sevillanos. En este proceso participaron la Iglesia, la Corona y los gremios, erigiéndose un creciente número de establecimientos orientados a favorecer asistencialmente a sectores sociales desfavorecidos.

Momentos después de la conquista, Fernando III dispuso la fundación del Hospital de San Lázaro para los malatos, colectivo que era extirpado de la sociedad mediante el ceremonial de la separatio leprosorum ${ }^{2}$. La Corona no tardó en fomentar nuevos centros bajo su patrocinio, surgiendo el Hospital Real, instituido por Alfonso XI, como asilo para soldados impedidos ${ }^{3}$ y que, en origen, estuvo vinculado a una cofradía que daba culto a la Virgen del Pilar ${ }^{4}$.

A finales de la Edad Media y durante la Edad Moderna, la red hospitalaria experimentó cambios significativos, surgiendo nuevos centros fundados por iniciativa privada que constituirían un revulsivo en el panorama local sanitario. La fundación del Hospital de San

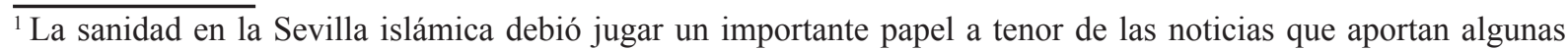
fuentes de carácter jurídico. El Tratado de Ibn 'Abdûn, cadí coetáneo del rey Al Mutamid, admitía la necesidad de un «médico experto y de conciencia» para garantizar la salud de la población, señalando que era una de las profesiones indispensables que debían existir en toda sociedad (García Gómez, Emilio y Évariste Lévi-Provençal, Sevilla a comienzos del siglo XIII. El tratado de Ibn Àbdûn, Sevilla, Ayuntamiento de Sevilla, 1992, p. 169). Con todo, aunque parece constatarse la existencia de centros hospitalarios especializados en la Sevilla musulmana, la inexistencia de fuentes directas sobre los mismos impide un exhaustivo conocimiento de ellos (Martínez Pérez, Felipe, "La medicina sevillana en el siglo XIII", en Archivo Hispalense, 12, 39-41 (1950), pp. 140-141).

${ }^{2}$ Moreno Total, Esteban, Estudio social y farmacoterapéutico de la lepra: el Hospital de San Lázaro de Sevilla (S.XIII-XIX), Sevilla, Diputación Provincial de Sevilla, 1997, p. 35. En 1179, el III Concilio de Letrán ordenó una serie de disposiciones destinadas a que los leprosos fuesen separados de la sociedad como medida profiláctica. Más allá de sus implicaciones sanitarias, la lepra supuso una muerte social durante siglos (Kaufmann, Alicia et al., La lepra y sus imágenes. Enfermedad estigmática y muerte social, Madrid, Ministerio de Trabajo, 1985, pp. 20-21). ${ }^{3}$ Arana de Varflora, Fermín, Compendio histórico descriptivo de la mui noble y mui leal ciudad de Sevilla, metrópoli ínclyta de Andalucía, recopilado de los mejores authores que de dicha ciudad tratan, Sevilla, Imprenta de Manuel Nicolás Vázquez, 1766, pp. 41-42.

${ }^{4}$ Collantes de Terán, Francisco, Historia de la Hermandad y Hospital de Peregrinos que bajo la advocación de Nuestra Señora del Pilar existió en la ciudad de Sevilla, Sevilla, El Obrero de Nazaret, 1889, p. 37.
} 
Hermenegildo, promovido por el cardenal Juan de Cervantes en 1453 y destinado a los heridos ${ }^{5}$, fue un hecho trascendental porque se introdujeron novedosas aportaciones desde un punto de vista sanitario y administrativo ${ }^{6}$, sirviendo de modelo para otros establecimientos como el de las Cinco Llagas, fundado en 1500 por Catalina de Ribera para la atención de mujeres ${ }^{7}$.

A mediados del siglo XVI, el elevado número de hospitales y la incapacidad de muchos de ellos para cumplimentar sus funciones asistenciales, provocó que se suprimiesen setenta y cuatro institutos durante la reducción promovida por el cardenal Rodrigo de Castro a instancias de Felipe II $^{8}$, pasando sus bienes y rentas al Hospital del Espíritu Santo, de nueva creación, y al del Amor de Dios, del que se desconocen sus orígenes fundacionales ${ }^{9}$.

Las transformaciones internas de la red hospitalaria se plasmaron en la realización de nuevos textos constitutivos que vertebraban el día a día de los centros, prestando una atención especial a los procedimientos de gobierno, a la administración y a las prácticas sanitarias que se efectuaban con los pacientes ${ }^{10}$. Por ello, los estatutos resultan una fuente esencial para analizar las pautas de ingreso, la visita médica o la confortación espiritual que se ejercía con los enfermos.

Con todo, no siempre hubo una estricta observancia estatutaria, ya que eran frecuentes las remodelaciones procedimentales con el objetivo de adecuarse a circunstancias puntuales. Por esta razón, para la reconstrucción histórica de la asistencia, es imprescindible la consulta de otros documentos que posibiliten establecer la existencia de varios modelos de actuación en la hospitalidad durante la Edad Moderna.

Hace algunos años, María Luz López Terrada reivindicaba que, para el conocimiento de la asistencia sanitaria, no siempre había que acercarse al fenómeno hospitalario desde una perspectiva estrictamente médica, sugiriendo la necesidad de conocer los pormenores del funcionamiento de la institución ${ }^{11}$. Desde este punto de vista, es obvio que el estudio de tipologías librarias y documentales creadas para la administración de los dolientes nos acercan, desde un enfoque diferente, al conocimiento de los procesos relacionados con las prácticas asistenciales en la hospitalidad hispalense durante este periodo.

\footnotetext{
${ }^{5}$ Archivo de la Diputación Provincial de Sevilla [en adelante ADPSE], Hospital de San Hermenegildo, leg. 1 A, Sf. ${ }^{6}$ Aunque el fundador había dispuesto el hospital para todo tipo de enfermos, exceptuando los incurables, parece que durante el siglo XVII se especializó en la curación de heridos (González Díaz, Antonio Manuel, Poder urbano y asistencia social: el Hospital de San Hermenegildo de Sevilla (1453-1837), Sevilla, Diputación Provincial de Sevilla, 1997, p. 316).

${ }^{7}$ Collantes de Terán, Francisco, Los establecimientos de caridad de Sevilla, Sevilla, Ayuntamiento de Sevilla, 2009 , p. 17.

${ }^{8}$ Carmona García, Juan Ignacio, El sistema de hospitalidad pública en la Sevilla del Antiguo Régimen, Sevilla, Diputación Provincial de Sevilla, 1979, p. 191.

${ }_{9}^{9}$ López Díaz, María Teresa, Estudio histórico-farmacéutico del Hospital del Amor de Dios de Sevilla (1665-1755), Sevilla, Diputación Provincial de Sevilla, 1987, p. 45. La ausencia de medios económicos imposibilitó que muchos de ellos ejercieran una asistencia efectiva. Desde el siglo Xv hubo varios proyectos truncados por la oposición de cofradías (Chueca Goitia, Fernando et al., Los hospitales de Sevilla, Sevilla, Real Academia Sevillana de Buenas Letras, 1989, p. 53). Los primeros intentos de supresión se produjeron en 1488 (Collantes de Terán, Francisco. Los establecimientos... op. cit, p. 81) y, nuevamente, en 1507 (Carmona García, Juan Ignacio, El sistema de hospitalidad... op. cit., p. 178).

${ }^{10}$ García Martínez, Antonio Claret, "Las constituciones de los hospitales y los cuidados enfermeros en la España de los Austrias (siglos XVI-XVII), en Erebea, 4 (2014), p. 51.

${ }^{11}$ López Terrada, María Luz, "El hospital como objeto histórico: los acercamientos a la historia hospitalaria", en Revista d Història Medieval, 7 (1996), pp. 199-200.
} 
Para ello, el estudio tratará sobre dos procedimientos que marcaron los dos momentos trascendentales de la estancia del paciente en el hospital: el ingreso y la asistencia, la cual se vertebró a través de las continuas visitas médicas que se practicaban a lo largo del día.

\section{El ingreso y sus procedimientos: los libros de entrada de enfermos}

Los registros de enfermos constituyen uno de los vestigios documentales más antiguos que existen, ya que permiten la extracción de información puntual sobre la recepción e ingreso de los dolientes. Ya, en el templo de Epidauro existían grabados en los que se dejó constancia de las milagrosas curaciones que se realizaban por la divinidad ${ }^{12}$. Aunque se han considerado como registros, realmente se trataban de exvotos que se colocaban en agradecimiento al dios, si bien aparecían datos identificativos de las personas que habían recibido asistencia ${ }^{13}$.

De origen y finalidad distinta eran los antiguos registros medievales que hubo en el bimaristán u hospital de Nur-ed-Din de Damasco, construido en 1154. Gracias a la descripción del valenciano Ibn Yubayr, que recorrió Oriente Próximo entre 1183-1185, se conoce el procedimiento de ingreso a través de libros en los que se recogían los nombres de los enfermos y los gastos asociados a su manutención ${ }^{14}$.

Los registros más antiguos de la hospitalidad sevillana, llamados genéricamente libros de entrada y salida de enfermos, proceden del siglo XVII, por lo que hay que pensar que existieron, con anterioridad, otros instrumentos para el control de los pacientes de los que no han quedado vestigios documentales.

Los diferentes procedimientos de ingreso variaron según el establecimiento, adecuándose instrumentos librarios y documentales, en manos de oficiales y sacerdotes, en los que se anotaba una información puntual sobre el paciente. La diversidad de enfermedades y especializaciones que se trataban en los hospitales justificaba la adopción de distintas fórmulas y modelos procedimentales que se sustanciaron en libros y documentos, respondiendo a las connotaciones específicas de cada uno de los establecimientos sanitarios.

En este sentido, hay que destacar las divergencias existentes entre los hospitales que trataron un determinado segmento poblacional que padecía alguna dolencia. El Hospital de

\footnotetext{
${ }^{12}$ Herzog, Picard Charles, "Die Wunderheilungen von Epidauros, ein Beitrag zur Geschichte der Medizin und der Religion", en Revue des Etudes Grecques, 46 (1933), pp. 373-375.

${ }^{13}$ Pérez Tamayo, Ruy, De la magia primitiva a la medicina moderna, México D.F., Fondo de Cultura Económica, 2010, p. 32. En los exvotos se anotaba el nombre, edad y la profesión del enfermo junto a discursos sagrados Hieroi logoi - en los que se subrayaba el poder y la benevolencia de Asclepio (Phillips, Eustace Dockray, Greek Medicine, London, Thames and Hudson, 1973, p. 198). Los textos fueron objeto de estudio en la década de los años cuarenta del pasado siglo (Edelstein, Emma y Ludwig Edelstein, Asclepius. A collection and interpretation of the testimonies, Baltimore, The John Hopkins University Press, 1998).

${ }^{14}$ Bárcena, Carles G., "El bimaristán, un modelo de hospital islámico", en Natura Medicatrix, 62 (2001), pp. 7-8.
} 
San Lázaro, destinado a leprosos, o el Hospital de los Inocentes, para locos, usaron tipologías diferentes en las que se consignaba una determinada información. Todo lo contrario a otros hospitales en los que se atendían a personas con enfermedades comunes, como el de las Cinco Llagas, para mujeres con males no contagiosos, o el del San Hermenegildo, para heridos. Lo mismo puede indicarse de otros centros como el Hospital Real, que asistía a soldados impedidos. En cada uno de ellos se vertebró una normativa específica, en la que el ingreso no tenía por qué contar con el beneplácito de cirujanos y médicos.

Las constituciones más antiguas del lazareto hispalense, hospital decano de la ciudad, datan de 1393. En ellas, Enrique III dispuso un conglomerado normativo por el que se regularon todos los aspectos concernientes a los malatos de Sevilla y Cádiz, indicándose algunos pormenores sobre la recepción de enfermos. En este particular, no se contempló la creación de un libro registro, sino otro por el que se acreditaba la entrega de bienes que los leprosos hacían cuando ingresaban al centro. Este libro, a cargo del escribano de la casa, no nació con vocación de controlar el acceso o salida al hospital, sino para fiscalizar los bienes que estos aportaban al centro en contraprestación de la asistencia que iban a recibir ${ }^{15}$.

Durante la Edad Media, el ingreso en el lazareto se efectuaba cuando se realizaba la llamada declaración de leprosos, para la que se requería un riguroso examen practicado por un físico o médico, expidiéndose el documento acreditativo por parte de un alcalde de designación regia, como estipulaba la normativa de 1334 para el hospital ${ }^{16}$. Esta misma disposición se observó en otros lazaretos andaluces, como el de Granada, no conservándose ningún documento por el que pueda conocerse su estructura o contenido ${ }^{17}$.

A lo largo del Antiguo Régimen hubo diferentes formas de ingreso, dependiendo de las características de los establecimientos y de la naturaleza de las enfermedades o dolencias. Muchos de los hospitales funcionaron, más que como instituciones sanitarias, como hospederías, en los que primó un carácter selectivo del paciente sin necesidad de que interviniera el personal sanitario $^{18}$. La selección de enfermos se solía hacer mediante votos electivos de los cofrades o miembros de la hospitalidad. De todos modos, muchos de estos establecimientos, bajo el gobierno de cofradías que rendían devoción a una advocación, terminaron por ser suprimidos en la segunda mitad del siglo XVI, ya que no se consideraron hospitales, sino hospederías para pobres en los que, de manera puntual, se brindaba apoyo y sustento.

\footnotetext{
${ }^{15}$ ADPSE, Pergaminos, 228, f. 9v.

${ }^{16}$ Moreno Total, Esteban, Estudio social... op. cit., p. 136.

${ }_{17}$ Valenzuela Candelario, José, "Los leprosos de Granada en la ciudad de frontera. Expolio, desamparo y cristianización. La hospitalidad de San Lázaro (1496-1526)”, en Revista del CEHGR, 29 (2017), p. 78. Todavía, durante el primer tercio del siglo XVII, se mantuvieron pleitos judiciales promovidos por leprosos para que se reconociese su enfermedad por parte de la justicia. De este modo, en 1630 se siguieron autos a petición de Juan de Alba para que el hospital permitiese su ingreso como «posible enfermo de lepra» (ADPSE, Hospital de San Lázaro, leg. 26, Sf).

${ }^{18}$ Carmona García, Juan Ignacio, El sistema de hospitalidad... op. cit., p. 20.
} 
Como se ha indicado, los hospitales orientados a la asistencia sanitaria precisaron de unos procedimientos diferentes en los que, el diagnóstico médico, constituía el fundamento esencial para proceder al ingreso de un paciente.

Uno de los primeros hospitales en regular tales prácticas fue el de las Cinco Llagas, estableciéndose, en sus primitivas constituciones de 1503, que no se recibiese a ninguna enferma hasta que fuese vista por el médico, quien daba testimonio de que esta no padecía una enfermedad incurable o contagiosa, en cuyo caso se derivaba a otro hospital diferente ${ }^{19}$.

El hecho de que los médicos no residiesen en los hospitales con carácter permanente, circunstancia que sí se exigía al personal dedicado al gobierno y a la administración, produjo que, en determinadas ocasiones, llegasen enfermos en ausencia del cirujano o médico. Por esta razón, no era extraño que se produjese el ingreso con carácter provisional, haciéndose constar en el respectivo libro de entrada.

En algunos hospitales, como en el de Santiago de Compostela, se institucionalizó dicha práctica bajo el pretexto de que muchos enfermos llegaban a deshoras sin que se pudiese verificar su entrada, amaneciendo muertos tras pasar la noche a las puertas del edificio ${ }^{20}$. En Sevilla, esta circunstancia estaba contemplada en el proyecto estatutario de 1512 para el Hospital de las Bubas, aunque no se sabe si se llegó a practicar $^{21}$.

Puesto que el ingreso se solía hacer cuando el paciente había sido examinado por el médico del hospital, no se requería, salvo excepciones, ningún otro documento acreditativo expedido por otro profesional en el que se diera constancia de padecer alguna dolencia. Este documento sí se exigió, en cambio, en establecimientos de convalecientes como en el de Morón de la Frontera, donde la cédula del médico debía indicar el tiempo de ingreso y el tratamiento a seguir ${ }^{22}$.

El diagnóstico médico sirvió para disuadir a un buen número de personas que fingían algún tipo de dolencia para ser mantenidos por la institución durante un tiempo. De esta picaresca existen noticias fidedignas en las que se detallan algunas de las prácticas habituales; así, en 1598, el bachiller Cristóbal Pérez de Herrera, que había sido médico jefe de las galeras reales, publicó Discursos para la protección de los verdaderos pobres, la eliminación de simuladores, la fundación y el refugio de los pobres ${ }^{23}$. Algunas constituciones sevillanas, como las de 1513 del Hospital de las Bubas, hicieron referencia explícita a esta realidad, ordenándose que los enfermos fuesen echados de las enfermerías una vez hechas las curas:

\footnotetext{
${ }^{19}$ ADPSE, Hospital de las Cinco Llagas, leg. 1 A, doc. 3, f. 32v.

${ }^{20}$ Constituciones para el régimen y gobierno del Hospital Real de la ciudad de Santiago, y administración, cuenta y razón de sus bienes y rentas, Madrid, Imprenta Real, 1804, pp. 25-26.

${ }^{21}$ ADPSE, Hospital de San Cosme y San Damián, leg. 3 bis, doc. 1, Sf.

${ }^{22}$ Archivo Histórico Nacional [en adelante AHN], Osuna, C. 89, doc. 171, f. 7r-v.

${ }^{23}$ Bennassar, Bartolomé, La España del Siglo de Oro, Barcelona, Crítica, 2001, p. 203. Sobre la picaresca en torno a los falsos pobres y enfermos véase Carreño Rivero, Miryam, "Pobres vagabundas' en el proyecto de recogimiento de pobres y reforma social de Cristóbal Pérez de Herrera", en Revista Complutense de Educación, 8 (1997), pp. 20-42.
} 
Porque, como por esperiencia se ha visto, muchos de los dichos enfermos, después de sanos quedan tan horaganes (sic) [i.e. holgazanes] que no quieren servir, ni trabajar en sus oficios, o se abren llagas e fingen que tienen las mismas

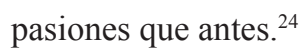

El ingreso hospitalario revestía, en el caso de los establecimientos para locos, un carácter diferente. Más que enfermerías al uso, el Hospital de los Inocentes contaba con habitaciones acondicionadas y calabozos donde los más violentos permanecían encerrados y encadenados ${ }^{25}$.

Bajo el término de locura se cobijaban una serie de conductas y enfermedades a veces difíciles de precisar para el personal sanitario. Durante el Antiguo Régimen, los locos sufrieron una estigmatización social difícilmente comparable a la de otros enfermos ${ }^{26}$, aunque sirvió de eximente condenatorio en los tribunales de justicia, costumbre arraigada desde la asunción del Derecho Romano en Occidente ${ }^{27}$.

Aquellos que precisaban la intervención del médico para su ingreso en el hospital eran personas que habían sido recogidas de las calles, enviadas por la Inquisición o procedentes de otras cárceles. Sin embargo, dado que en ocasiones el médico no era partícipe en la determinación del ingreso, la práctica que terminó por consolidarse en la Edad Moderna fue la del ingreso previo dictamen del médico, trabajase o no en el hospital, en cuyo caso se hacía necesario la exhibición de una cédula en la que se certificase padecer algún tipo de enfermedad mental o conducta extraña ${ }^{28}$.

Las ordenanzas de 1700 exigieron la obligatoriedad de que el médico del hospital practicase un reconocimiento del enfermo, viraje que estuvo motivado por las continuas irregularidades que se experimentaron durante los siglos XVI-XVII ${ }^{29}$.

Del Hospital de los Inocentes se han conservado varios expedientes que permiten establecer diferentes vías de ingreso. Lo habitual fue que se cursase petición al administrador, en la que se adjuntaba algún tipo de certificación de sacerdote o médico, siendo válidas ambas declaraciones. Los solicitantes también podían acudir al arzobispo, en cuyo caso este requería testimonio de varios sacerdotes, además de un informe otorgado por un médico experimentado.

Los clérigos juraban in verbo sacerdotis, procediendo a un simple diagnóstico a través de la conducta del enfermo, sin emplear para ello más palabras que la de «loco»o «demente».

\footnotetext{
${ }^{24}$ ADPSE, Hospital de San Cosme y San Damián, leg. 3 bis, doc. 2, s.f.

${ }^{25}$ Varias noticias detallan el aspecto de las celdas de reclusión, teniendo el hospital cadenas y grilletes para los enfermos más «furiosos». En el inventario de 1686 se dio constancia de "dies cadenas grandes y pequeñas", además de otra que estaba en la calle "donde suele estar un ynocente pidiendo" (ADPSE, Hospital de los Inocentes, lib. 1, Sf.).

${ }^{26}$ El hospital sufrió varios asaltos en los que se liberaron a los recluidos para ver qué hacían, sufriendo escarnio y mofa. Especialmente grave fue un asalto producido en el siglo XV, del que se dio parte a los Reyes Católicos, decidiendo amparar el establecimiento bajo su real patrocinio. Archivo General de Simancas [en adelante AGS], Registro General del Sello, leg. 147.710, doc. 52)

${ }^{27}$ Tropé, Hélène, "Los tratamientos de la locura en la España de los siglos XV al XVIII. El caso de Valencia", en Frenia. Revista de Historia de la Psiquiatría, 11 (2011), p. 35.

${ }^{28}$ López Alonso, Carmen, Locura y sociedad en Sevilla: historia del Hospital de los Inocentes (1436?-1840), Sevilla, Diputación Provincial de Sevilla, 1988, pp. 50-51.

${ }^{29}$ Ibídem, p. 136.
} 
No era infrecuente que se adjuntasen informaciones particulares de testigos que ratificasen la estrambótica o irregular conducta de una persona.

Uno de los casos más paradigmáticos, que confirma tales prácticas, lo constituye el expediente formado, en 1663, por el párroco Diego de Ulloa sobre Juan Ruiz Mancha, de la pedanía estepeña de La Roda, apareciendo el sacerdote como ordenante del proceso. El testimonio de este dejaba claro que era un demente -"Dios, Nuestro Señor, ha sido seruido de darle demencia"-, y adjuntaba varias testificaciones en apoyo de su diagnóstico. Entre ellas, destacaba la de Pedro Rastrero, alcalde ordinario, que afirmó que se "le oye de día y de noche los muchos disparates que habla, unas veces cantando, otras jurando, otras enaxenándose con las personas".

Junto al estamento clerical, el civil también podía solicitar el ingreso sin necesidad aparente de intervención médica. Así, en 1682, se formó un expediente sobre el sanluqueño Pedro Velázquez, cuyo caso particular reviste tintes dramáticos por haber sido acusado de asesinar a una niña de dieciocho meses. Condenado a prisión y galeras, pudo ingresar en los Inocentes gracias a la intervención del sacerdote Diego de Santana, que pidió fuese llevado a la «cárcel de San Marcos de Sevilla», apelativo con el que se refería al hospital.

Además de las peticiones de particulares dirigidas al administrador, y que llevaban anejas certificaciones de la fe pública con la declaración de testigos, existen muchos casos en los que fue la Corona quien ordenaba el ingreso de algún soldado. Este procedimiento se ventilaba a través de una real cédula a petición de algún oficial del ejército, que previamente había informado de la irregular conducta de algún miliciano, como sucedió en 1726 cuando el administrador anotó la entrada en el centro del subteniente Domingo de Urbina, del regimiento de infantería de Soria, "que por demente está incapaz de continuar su mérito en el ejército". En estos casos, la manutención del enfermo corría a cargo de la Real Hacienda, librándose el pago mensual.

Desde la segunda mitad del siglo XVII se aprecia un aumento de las certificaciones médicas como requisito de ingreso. Estos documentos aportaban una información relevante sobre el paciente porque, en ellos, los médicos trataban de explicar las causas de la demencia. Francisco Sánchez, médico revalidado de los Reales Alcázares de Sevilla, remitió un completo informe sobre Paula del Pulgar y Mora en 1759 explicando que estaba demente a consecuencia de "un tabardillo en la cabeza, cuyo principio fue con un fuerte delirio que, hauiendo sido invencible en dicha enfermedad, a durado hasta el presente de la fecha, sin obediencia a remedio alguno, más que a prisión con cadena, la que de continuo tiene por cortar mayores daños y riesgos de su vida" [fig. 1]. 
Figura 1 Certificación médica para ingreso en el Hospital de los Inocentes de Sevilla, 1759.

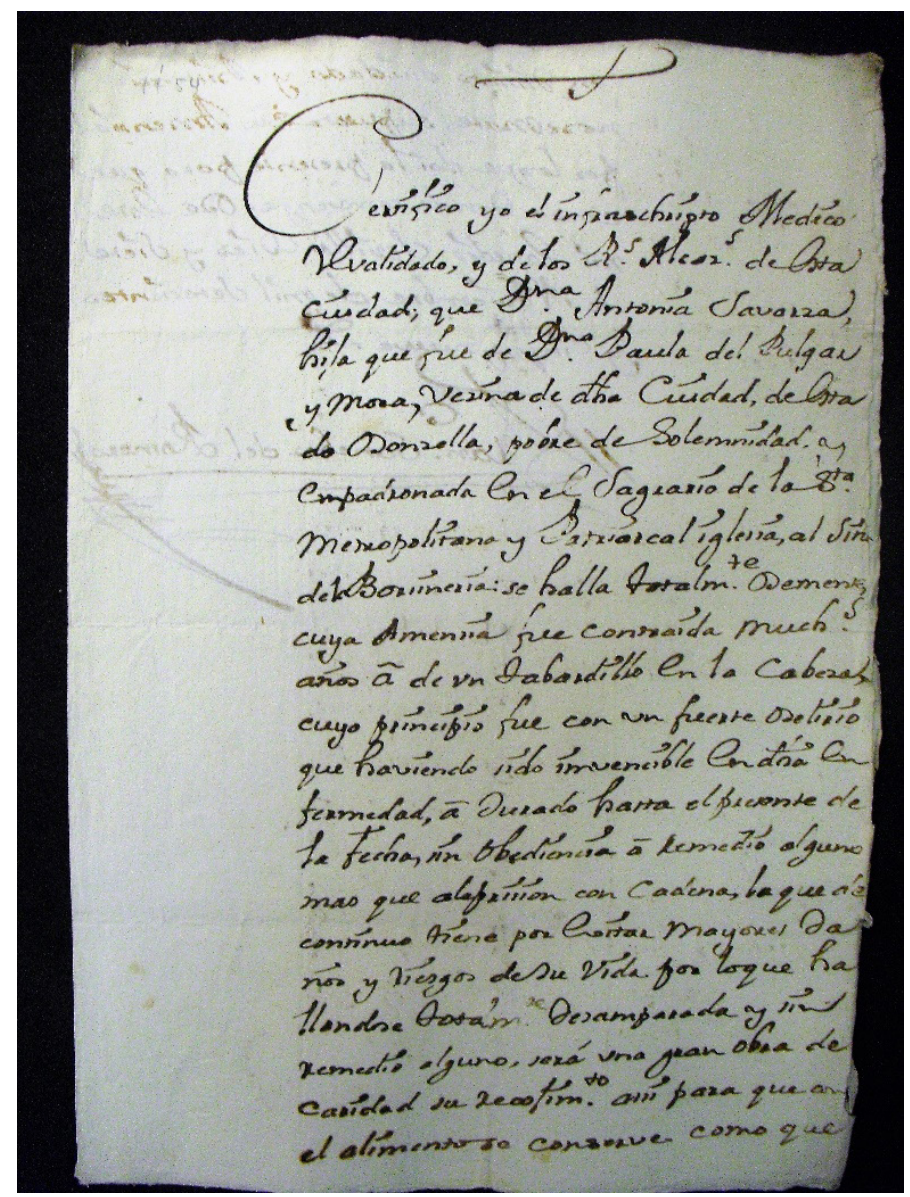

Fuente: ADPSE, Hospital de los Inocentes, leg. 51.

A diferencia de otros hospitales, en el de los Inocentes se podían cursar sucesivas altas e ingresos del mismo paciente por razones de mejoría, previo dictamen médico. Así mismo, la institución responsable de cursar solicitud de ingreso podía exigir su devolución sin previo consentimiento del sanitario. Esta vía parece haber quedado reservada para cuando el enfermo había sido entregado por la justicia civil o eclesiástica. De este supuesto existe algún que otro expediente, como el del morisco Alonso Moreno, que había sido remitido por la Inquisición y que salió por exigencias del mismo Tribunal en 1600 por “justas causas"30.

Todos los hospitales emplearon mecanismos de control para el ingreso, dejando constancia de significativos datos de los pacientes en los denominados libros de entrada de enfermos, que conforman una de las series documentales más estables en la hospitalidad hispalense.

Los libros de entrada tuvieron una utilidad diversificada y, aunque su puesta por escrito no dependió del personal sanitario, se requería de su licencia previa como modo de admisión del paciente al centro hospitalario. Dependiendo de las características de la institución y de las

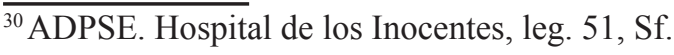


enfermedades o dolencias que atendía, el libro adquiere unas características tipológicas únicas, si bien los datos que se consignaban en los asientos solían estar estandarizados, registrándose siempre los de carácter personal como forma de identificación del paciente.

Las primitivas constituciones de los hospitales sevillanos no contemplaban su existencia, motivo por el que los registros más antiguos son del siglo XVII. En esta centuria se produjo un significativo viraje en los estatutos de los principales centros sevillanos, plasmándose con rigurosidad los diferentes procedimientos administrativos con indicación de las tipologías librarias y documentales que debían emplearse.

De esta manera, si las constituciones de 1503 del Hospital de las Cinco Llagas solo prestaban atención al recibimiento de enfermas y a la praxis que debía seguirse para la asignación de cama, las de 1624 especificaron todo lo concerniente al libro de entrada:

\begin{abstract}
Abrá vn libro en que, con puntualidad, se escriban los nombres de las enfermas que entran a curarse en este hospital, y la ropa que traen, y si trugeren algún dinero, y se pondrá en una sala que para este efecto estará diputada, escribiendo ençima de cada vestido, en una çedulilla, el nombre de cuyo es y a qué número está acostada. Y, quando se vaya, se escriuirá a la margen del libro el día que sale, y se le dará su vestido, y la enferma que muriere, su vestido se lleuará a la sala, para que se uenda para hazer bien por su alma, y se aduertirá en el libro el día que murió, y quién la uió muerta y, por señal, una cruz. ${ }^{31}$
\end{abstract}

El contenido de los libros de entrada podía ser variopinto, existiendo una relación de estos con otros libros de fines diferentes. Además de servir para identificar al paciente, tenían el objetivo de servir como inventario de los bienes que llevaban los enfermos, de los que eran despojados con carácter inmediato, entregándoselos a la madre ropera, que tenía otro libro con el mismo contenido. Todos los pacientes estaban obligados a guardar esta normativa como medida profiláctica y se aplicaba en aquellos hospitales en los que el ingreso podía ser prolongado. El Hospital de San Hermenegildo también exigía estas medidas, debiendo vestir el paciente una ropa concreta dependiendo de la época del año ${ }^{32}$.

A través de los libros de entrada y salida de enfermas del Hospital de las Cinco Llagas pueden concretarse las modificaciones que se fueron realizando a lo largo de los siglos XVII y XVIII. El primer libro que se conserva (1604-1609), está dividido por meses y en cada asiento se anotaban los nombres de las pacientes, su estado, procedencia y la ropa que traía consigo. Si la mujer estaba casada se expresaba el nombre del marido y si era viuda o doncella bastaba con su procedencia. Puesto que los asientos no siguen estrictamente un orden cronológico de días, hay que pensar que su puesta por escrito pudo realizarse cuando la enferma estaba ya en la enfermería, una vez había pasado el diagnóstico del médico. A uno de los márgenes, el cura

\footnotetext{
${ }^{31}$ ADPSE, Hospital de las Cinco Llagas, leg. 1, doc. 3, ff. 4v-5r.

${ }^{32}$ González Díaz, Antonio Manuel, Poder urbano... op. cit., p. 316.
} 
semanero, encargado de su puesta por escrito, hacía constar la fecha de la defunción, por lo que aquellos asientos que carecen de este dato indican que la enferma fue dada de alta ${ }^{33}$.

Esta misma estructura se mantuvo en todos los libros del siglo XVII, añadiéndose desde 1625 el número de la cama, dígito que se empleó como identificador de la enferma en diferentes procedimientos sanitarios durante su estancia en el hospital. En los supuestos de que el establecimiento no tuviese camas suficientes, las enfermas eran dispuestas en las inmediaciones de las enfermerías y las salas de cirugía. En tal caso, el cura lo hacía destacar indicando el espacio en el que se encontraba — -pasillo de salita... suelo del caracol... suelo de çirujía" - 34 .

Las anotaciones marginales que no se referían a la muerte de la enferma siempre responden a alguna particularidad excepcional. De este modo, durante el contagio de peste de 1649, el Hospital de las Cinco Llagas sirvió como establecimiento en el que se dio cobijo a un importante número de personas de ambos sexos para paliar la calamitosa situación que experimentó la urbe. A pesar de la excepcionalidad, las enfermerías destinadas a curar enfermas que padecían dolencias no contagiosas siguieron en funcionamiento. Muchas de ellas, una vez que habían entrado y estaban en cama, dieron síntomas de contagio, procediéndose a su inmediato traslado. Esta circunstancia quedó anotada en el libro por primera vez el 21 de abril de 1649 — “murió declarada y no ubo lugar de lleballa"_- ${ }^{35}$. Desde ese día, los curas apuntaban si padecía la peste o no escribiendo "declarose y salió". A través de este interesante libro, puede comprobarse la instalación de una enfermería especializada para tratar del mal contagioso desde el 2 de mayo.

Todo apunta a que los procedimientos de ingresos se endurecieron ese año, ya que se establecieron filtros médicos que paliaban el contagio de las enfermas comunes de las contagiosas. De hecho, desde el 9 de mayo de 1649 no se registró ningún caso de enferma a la que se tuviese que trasladar, destinándose otros instrumentos documentales para el asiento de los aquejados por peste.

Estos libros también tuvieron una finalidad fiscalizadora, pues se usaron para ajustar los balances económicos a tenor del número de enfermos y los gastos existentes para su mantenimiento y asistencia sanitaria, motivo por el que eran examinados por los visitadores hospitalarios. Por esta razón, no extraña que las constituciones de 1513 del Hospital de las Bubas no contemplasen la existencia de un libro en exclusividad para el asiento de enfermos, sino que estos se computasen en el de gastos ${ }^{36}$.

En el Hospital del Pozo Santo tampoco hubo, en origen, un libro destinado para el control de enfermas impedidas, sino que se hacía en otro donde de escribían "las cossas más principales". La madre mayor era quien anotaba en una hoja las que estaban internas y, en otra, las que lo habían solicitado ${ }^{37}$.

\footnotetext{
${ }^{33}$ ADPSE, Hospital de las Cinco Llagas, leg. 242, libro de 1604-1609.

${ }^{34}$ ADPSE, Hospital de las Cinco Llagas, leg. 242, libro de $1625-1627$, ff. $217 \mathrm{v}$ y $220 \mathrm{r}$.

${ }^{35}$ ADPSE, Hospital de las Cinco Llagas, leg. 242, libro de 1648-1663, f. 37v.

${ }^{36}$ ADPSE, Hospital de las Bubas, leg. 3 bis, doc. 2, Sf.

${ }^{37}$ ADPSE, Hospital del Pozo Santo, leg. 3, f. 8r.
} 
Aunque los asientos no conforman un expediente personal del enfermo, ni tampoco su historial clínico, es obvio que en algunos libros se apuntaron las causas del ingreso, aspecto rara vez observado en el conjunto de los hospitales sevillanos. El motivo de esta información puede encontrarse no solo en la finalidad del registro, sino en la especialización hospitalaria que había en la ciudad. En este sentido, parece razonable pensar que, en los registros de enfermos de los lazaretos, no fuese necesario hacer constar que padecían lepra, como tampoco se hacía en el de los sifilíticos. Ahora bien, en el Hospital de San Hermenegildo, especializado en heridos, fue frecuente durante el siglo XVIII especificar la causa del ingreso y la dolencia que padecía, pudiendo llegar a informar sobre otros particulares de la herida ${ }^{38}$ [fig. 2].

Figura 2: Libro de entrada de enfermos del Hospital de San Hermenegildo, 1721.

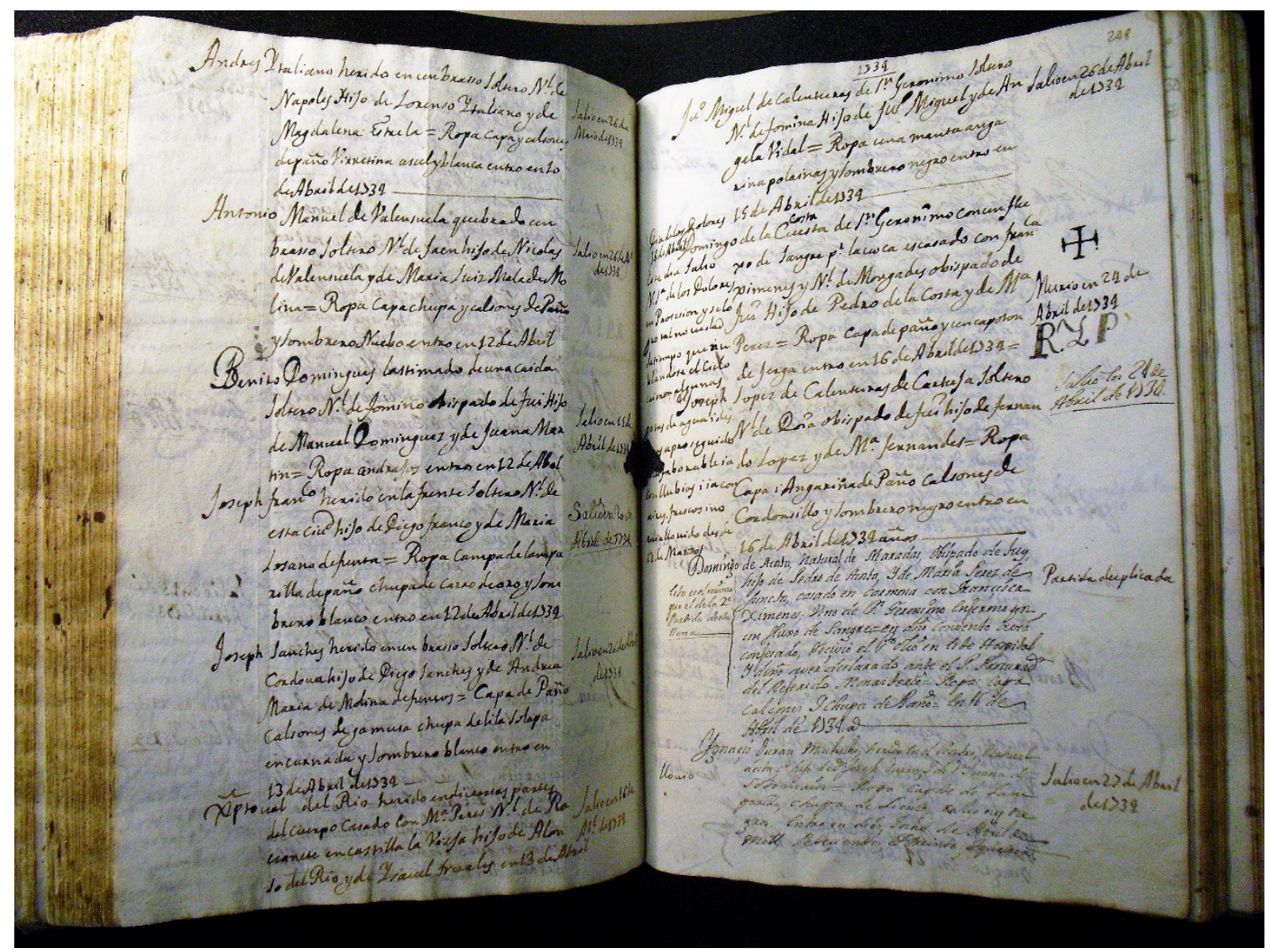

Fuente: ADPSE, Hospital de San Hermenegildo, lib. 15.

Durante el siglo XIX los registros empezaron a contener más información; en el Hospital de las Cinco Llagas se anotaba la relación de ingresos, los motivos de este, la causa de la

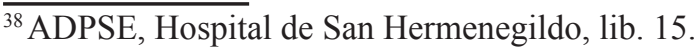


muerte, con copia literal del diagnóstico médico, y el certificado de defunción extraído del libro de enterramientos ${ }^{39}$.

Si bien al principio los libros de entrada no estuvieron bajo responsabilidad de los médicos ${ }^{40}$, con el tiempo, el personal sanitario intervino en su puesta por escrito; así, durante el siglo XVIII se hizo necesaria la firma del médico en cada uno de los asientos, quedando constancia de su participación en la aceptación del ingreso del paciente. Esto mismo fue lo que se ordenó por el juez examinador José Martínez Pons, regente de la Real Audiencia de Sevilla, en el Hospital de los Inocentes por auto de visita el 4 de octubre de 1770:

\footnotetext{
Que en el libro de entradas note, precisamente, en la margen, la concurrencia y aprovación de médico en la admición y salida, con rúbrica del mismo [médico] e interbención del contador de la casa, para que conste el número de enfermos y enfermas que ai. ${ }^{41}$
}

Como se ha indicado, la estructura fue análoga en la mayoría de los hospitales sevillanos, aunque el hecho de la existencia de enfermerías divididas para hombres y mujeres no condicionó, como en otros lugares, que se hiciesen dos registros diferentes en libros separados, observándose únicamente en el Hospital del Espíritu Santo, del que se conservan registros de 1663 a $1810^{42}$.

Cada uno de los asientos están estructurados de manera semejante, en la parte central se escribían todos los datos personales del paciente, los bienes que traía y el estado que presentaba, dejándose los márgenes para anotar la fecha de alta, mediante la expresión "salió", con indicación de la data, o la muerte, para lo que se empleó el signo de la cruz. Si el paciente moría se explicitaba la recepción de los sacramentos, las misas que se habían hecho por su sufragio y si había recibido sepultura en el cementerio del establecimiento.

Paradigmáticos resultan los del Hospital de los Inocentes, ya que con frecuencia se efectuaban ingresos y altas dependiendo de la mejoría del paciente o si algún familiar solicitaba su salida. A pesar de que se requería diagnóstico y alta por orden y parecer del médico, esta información no se hizo constar en los asientos.

El primer libro que se ha conservado se comenzó a escribir en 1679, a instancias del oidor de la Real Audiencia de Sevilla, García Fernando Bazán, en cuyo auto se explicaba su utilidad, aludiendo a su uso contable y al desorden que hasta ese momento se había tenido en los registros:

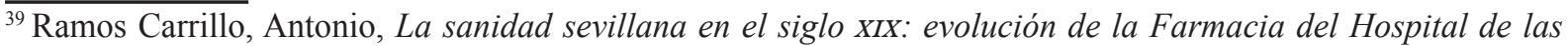
Cinco Llagas, tesis doctoral inédita, Universidad de Sevilla, 2000, p. 411.

${ }^{40}$ En efecto, la responsabilidad de la puesta por escrito de los libros recaía en los oficiales y sacerdotes del establecimiento. En este sentido, las ordenanzas de 1603 del Hospital de las Cinco Llagas reservaron al sacerdote encargado de la confortación espiritual de las enfermas la obligatoriedad de escribir los asientos en los libros (ADPSE, Hospital de las Cinco Llagas, leg. $1 \mathrm{~A}$, doc. 1, Sf).

${ }^{41}$ ADPSE, Hospital de los Inocentes, leg. 11, n. ${ }^{\circ} 5$, f. 4v.

${ }^{42}$ Barriga Guillén, Carmen et al., Hospitales y centros benéficos sevillanos. Inventarios de sus fondos, Sevilla, Diputación Provincial de Sevilla, 1997, pp. 292-293.
} 


\begin{abstract}
Assí para la quenta del hospital, como para poder dar las notiçias de vida o muerte de los enfermos en las ocasiones que fueren neçessarias, ya para sus intereses y derechos del hospital y, ya, para sus parientes, padres, maridos o mugeres de los enfermos, en que hasta aora ha auido grandíssimo defecto y descuido. $^{43}$
\end{abstract}

Los libros de enfermos del Hospital de las Bubas son los que menos información ofrecen y cuya estructura interna difiere de los demás. Además de distinguir asientos por enfermerías, se subdividía por camadas, nombre con el que se denominó a los aguajes que se hacían durante determinados meses del año ${ }^{44}$.

Aunque la finalidad de estos libros no era la de realizar un estudio estadístico del número de ingresos, curaciones, altas o defunciones, en algunos establecimientos se empezaron a hacer recuentos del número de ingresos y defunciones, metodología que se siguió en el Hospital de San Hermenegildo ${ }^{45}$, en el del Espíritu Santo desde $1680^{46}$ y en de las Cinco Llagas desde $1787^{47}$

\title{
3. La visita médica: prescripción y libros de botica
}

La visita médica constituía la principal práctica en la que se daban encuentro el personal sanitario y el enfermo. En ella, el médico realizaba su diagnóstico y prescripción para la preparación de las fórmulas por parte del boticario y la dieta alimentaria que debía dispensarse en ese día.

El médico realizaba una o varias visitas diarias acompañado por oficiales y sacerdotes, ya que los establecimientos estaban considerados como lugares preparatorios del alma para afrontar una eventual muerte. El cuidado y la atención eran uno de los aspectos más regulados por las constituciones, hasta el punto de que, las de 1696 del Hospital de Nuestra Señora del Amparo del Puerto de Santa María, advertía a los médicos que atendiesen a los enfermos con caridad y cuidado por ser ellos quienes, en ese momento, representaban la caridad divina ${ }^{48}$.

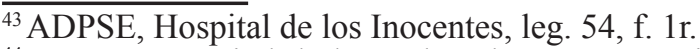

${ }^{44}$ ADPSE, Hospital de las Bubas, leg. 42. A partir de 1734 se empezó a registrar el nombre de los cónyuges o familiares, práctica que no se efectuó hasta ese momento.

${ }^{45}$ ADPSE, Hospital de San Hermenegildo, lib. 15.

${ }^{46}$ ADPSE, Hospital del Espíritu Santo, leg. 185 A

${ }^{47}$ ADPSE, Hospital de las Cinco Llagas, leg. 248, libro de 1766-1798.

${ }^{48} \mathrm{AHN}$, Códices, lib. 1.169, f. 12r. La asistencia a bien morir era una parte esencial en la caridad hospitalaria y, aunque estaba reservada a los sacerdotes, los enfermeros empezaron a desempeñar tareas orientadas a confortar al paciente. En 1598 se dispuso en el Hospital de San Hermenegildo que los enfermeros tomasen parte del cuidado anímico y espiritual por ser los que más tiempo pasaban en contacto con los enfermos (ADPSE, Hospital del
} 
El diagnóstico debía hacerse mediante preguntas verbales y observación directa del médico o cirujano, motivo que justifica la inexistencia de documentos que recogiesen los cuestionarios médicos. Con todo, las primitivas constituciones del Hospital de la Santa Cruz de Toledo, fundado por el cardenal Pedro González de Mendoza en 1496, sí recogían, en el tenor normativo, los aspectos que debía considerar el médico durante la visita:

\begin{abstract}
Ha de preguntar a cada enfermo lo que combiene sauer cerca de su enfermedad, i del tiempo que ha que la tiene, i de las vezes que ha purgado o xaropado y sangrado, i de lo que le dan a comer i beuer, i si le an dado las mediçinas que el día antes le mandó dar. ${ }^{49}$
\end{abstract}

Desde el punto de vista de la producción documental, la visita era el eje central en el que participaron varios sujetos de forma conjunta, siendo el médico el responsable de la expedición de recetas y, dimanando de su autoridad, las dietas a las que los pacientes se veían sometidos durante su ingreso. Sin embargo, aunque la receta escrita en papel, en forma de cédula, existía ya en este tiempo, no se tuvo costumbre de expedirlas en este formato en la hospitalidad sevillana, ya que la mayor parte de los hospitales contaban con botica propia y el boticario estaba presente durante la prescripción. Muchos de los documentos resultantes de la visita no se han conservado al estar escritos en un soporte diferente al papel que permitía el borrado y su reutilización. Lo habitual fue emplear tablas de pizarra o de madera barnizadas en las que se apuntaba todo lo ordenado verbalmente por el médico. Esta metodología fue la más empleada durante el siglo XVI y buena parte del siglo XVII, modificándose el procedimiento durante la Ilustración.

El uso de tablillas estuvo muy extendido; así, las primeras constituciones del toledano Hospital de la Santa Cruz disponían que el boticario debía ir "con la tabla para saber lo que manda dar el físico a cada uno", la cual se colocaba sobre el cobertor de la cama de cada paciente para evitar confusión en la dispensación de medicamentos ${ }^{50}$. En el Hospital de San Hermenegildo de Sevilla se hizo de forma análoga durante los siglos XV y XVI, acompañando

Cardenal, lib. 1 A, f. 69v). Los hospitales solían tener algún crucifijo o imagen religiosa que era llevada al paciente para ayudarle a bien morir, recogiéndose su existencia en algunos inventarios - "un crucifixo de plomo con su sitial y cortinita carmesí para ayudar a bien morir a las enfermas, con su pie de madera"- (ADPSE, Hospital del Espíritu Santo, leg. 2 C, f. 52r). Además, se podían realizar lecturas sacras para ayudar a la confortación del alma, como se practicaba en el Hospital de las Cinco Llagas (Mestre Navas, Pablo Alberto, "Libros hospitalarios sevillanos en la Edad Moderna", en Titivillus, 2 (2016), p. 163, DOI «https://doi.org/10.26754/ojs titivillus/ titivillus.201603134»). Las ordenanzas de 1603 del Hospital de las Cinco Llagas dedicaron algunas líneas a la praxis que debía seguir el personal de la enfermería cuando una enferma estaba agonizante: «...quando la enferma estubiere en agonía se le ponga una mesa delante con un crucifijo ençima y el açeite con agua bendita y ysopo y una bela enzendida, y a ella la pongan otra bela enzendida en la mano, y que asistan el cura, las enfermeras que se pudieren desocupar y las enfermas conbaleçientes que tubieren dispusiçión para ello, y todos le ayuden a bien morir, y acabada de finar el cura diga en alta boz "difunnta tenemos, rogad a Nuestro Señor le de su gloria, y reçad cinco abe marias con cinco padrenuestros por su ánima" (ADPSE, Hospital de las Cinco Llagas, leg. 1 A, doc. 1, $\mathrm{Sf})$.

${ }^{49}$ AHN, Osuna, C. 3, doc. 23, Sf. Estas constituciones fueron copiadas, junto a la de otros hospitales europeos, por orden de Juan Téllez-Girón, IV conde de Ureña, para la redacción de las del establecimiento que iba a fundar en Osuna, llamado Hospital de la Encarnación. Las constituciones aprobadas en 1739 en el hospital de Toledo fueron objeto de estudio hace algunos años [Santolaya Heredero, Laura, "Las constituciones del hospital de Santa Cruz (Toledo)", en Espacio, Tiempo y Forma, Serie IV, H' Moderna, 3 (1990), pp. 317-366].

${ }^{50}$ AHN, Osuna, C. 3 , doc. 23 , Sf. 
al médico un sacerdote que apuntaba la comida, así como el boticario, que hacía lo propio con las medicinas. Durante el siglo XvII se mantuvo la tabla para uso del sacerdote, en la que asentaba el nombre del paciente y el número de cama, con expresión de los alimentos mediante la utilización de signos abreviados. De esta forma, se escribía una "G" si debía comer gallina, "P" si era pollo y "C" si la cocina debía dispensar carnero como dieta ${ }^{51}$.

Las constituciones de 1524 del Hospital de Santiago de Compostela también indicaban que, en la visita del médico, debían ir el boticario y el enfermero mayor. Era al menor a quien le correspondía anotar las órdenes del médico en una tabla de yeso, haciendo lo propio el boticario en su respectivo libro ${ }^{52}$.

Paulatinamente, se fueron sustituyendo las tablas, que quedaron para su colocación en las camas de los pacientes, consignándose el número de cama, nombre del enfermo, alimentos que este debía comer en el día y las purgas o sangrías que se debían efectuar, por el uso de libros especializados para el boticario, en los que se informaba de las medicinas.

La numeración de las camas sirvió para vertebrar la estructura interna de los libros de botica de algunos hospitales, dividiéndose en asientos por dígitos sin necesidad de expresar el nombre del doliente. Este sistema de anonimato sirvió para evitar una posible reduplicidad de nombres y que ello provocase un error en la dispensación de los fármacos. Sin embargo, hay quien ha visto en ello un método que posibilitó atender a pacientes extranjeros, de nombres muchas veces difíciles de escribir ${ }^{53}$.

De todos modos, los hospitales acostumbrados a recibir enfermos de diferentes nacionalidades contaban con sacerdotes políglotas, o naturales de otros países, que servían de intérpretes para los médicos, además de encargarse de su confesión, condición imprescindible antes de cualquier ingreso hospitalario en el Antiguo Régimen ${ }^{54}$.

Como dispensarios de medicinas y laboratorios de preparación, la botica era uno de los espacios más importante de los establecimientos sanitarios. No todos los hospitales sevillanos, durante la Edad Moderna, contaron con botica propia. En San Lázaro, por ejemplo, no hubo botica, por lo que no se ha conservado ninguna documentación sanitaria que permita conocer qué tipo de atención sanitaria recibieron los leprosos en este periodo, además de los baños que tomaban en el próximo Guadalquivir y otras medidas higiénicas ${ }^{55}$.

En el Hospital de las Bubas tampoco consta la existencia de botica, motivo por el que el administrador adquiría los medicamentos en otros hospitales o en boticas privadas de la ciudad. De este hospital se han conservado hasta siete listados de medicamentos, fechados entre 1570

\footnotetext{
${ }^{51}$ Herrera Dávila, Joaquín, El Hospital del Cardenal de Sevilla y el doctor Hidalgo de Agüero: visión histórico sanitaria del Hospital de San Hermenegildo (1455-1837), Sevilla, Fundación de Cultura Andaluza, 2010, p. 151.

${ }_{52}$ Constituciones del Gran Hospital Real de Santiago de Compostela, hechas por el señor emperador Carlos Quinto, 1590, p. 31.

${ }_{53}$ Zamorano Rodríguez, María Luisa, Historia del Hospital de San Juan Bautista de Toledo durante el siglo XVI, tesis doctoral inédita, Universidad Complutense de Madrid, 1992, p. 194.

${ }^{54}$ Ya, Alfonso x el Sabio estableció en su célebre código la necesidad de que los cristianos recibiesen atención espiritual antes de ser atendidos por físicos, tal y como ordenó en la Part. I, tit. IV, ley XXXVII.

${ }_{55}$ Moreno Total, Esteban, Estudio social... op. cit., p. 150.
} 
y 1598. En el encabezamiento de todos aparece el nombre del administrador, seguido de los compuestos o productos que se debían adquirir y el precio ${ }^{56}$ [fig. 3].

Sin embargo, los grandes hospitales sevillanos, aquellos que nacieron como consecuencia de la reducción del siglo XVI o los que subsistieron a ella, contaban con boticas bien provistas y con el personal necesario para su atención. El estado e instrumental de las boticas sevillanas puede estudiarse a través de los numerosos autos de visita que se practicaron durante la Edad Moderna. Todo ello se verificaba por parte del administrador o los patronos de los establecimientos, quienes iban acompañados por el médico para supervisar el buen estado de las medicinas y compuestos.

Figura 3. Relación de medicamentos para el Hospital de las Bubas, 1598.

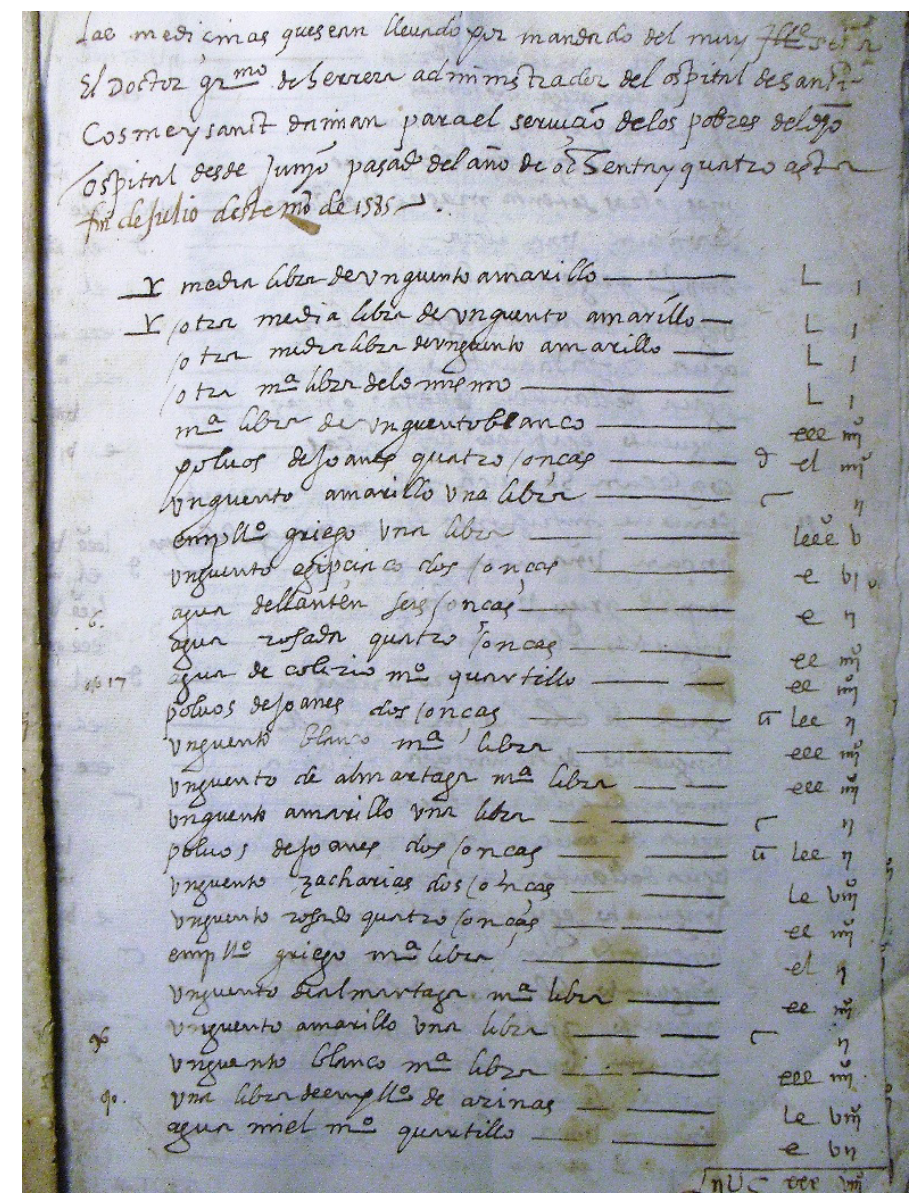

Fuente: ADPSE, Hospital de las Bubas, leg. 37.

Muchas de ellas contaron con un ordenamiento jurídico propio, aunque los estatutos hospitalarios de la Edad Moderna ya prestaron una atención especial a todo lo concerniente a su gobierno y proveimiento.

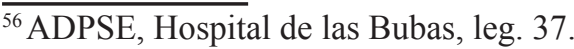


A través de los diferentes inventarios que se han conservado, pueden reconstruirse los repertorios bibliográficos de medicina y farmacopea que los boticarios emplearon durante la Edad Moderna como libros de consulta para la confección de los medicamentos.

Sevilla contaba con una buena tradición en esta materia. No en vano, se suele considerar como el primer libro de Farmacia escrito en castellano el Modus faciendi cum ordine medicandi, escrito por fray Bernardino de Laredo, del sevillano convento franciscano de Villaverde del Río, y que fue impreso en la ciudad en 1527, 1534 y $1542^{57}$. Además, el sector farmacéutico había experimentado un notable crecimiento en la ciudad durante el siglo XVI, hasta el punto de que algunas de las primeras boticas adquiridas por los hospitales indianos procedieron íntegramente de la capital andaluza, como la que adquirió el limeño hospital de Santa Ana en 1549 de Pedro de la Palma por 3.400 pesos de oro ${ }^{58}$.

Una de las boticas mejor provistas de la ciudad, en lo que se refiere a repertorios bibliográficos, fue la del Hospital de las Cinco Llagas ${ }^{59}$, aunque las del Amor de Dios, San Hermenegildo y Espíritu Santo contaban también con un buen número de libros.

El 25 de junio de 1692, el administrador del Hospital del Amor de Dios, Juan Francisco Cardiel, acompañado del médico Miguel Aiza, anotó la existencia de cinco libros, que correspondían a los de "Obiedo, Dioscórides, de Messue, de Gerónimo de la Fuente y de Miguel Martínez". Estos cinco ejemplares fueron los que se mantuvieron durante buena parte del siglo XVII, inventariándose, en la visita efectuada en 1695, otro de "Diego Vélez", y uno de "Bernardo Pérez" en $1710^{60}$.

En el Hospital de San Hermenegildo, además de contar con varios libros de consulta en la botica ${ }^{61}$, se tuvo costumbre de encuadernar algunos de los documentos privados que los médicos de la casa habían dejado sobre prácticas curativas. En este sentido, en sus enfermerías se siguió practicando la vía particular establecida en el centro por el célebre Bartolomé Hidalgo de Agüero, que había resultado bastante exitosa. Por este motivo, los patronos del establecimiento exigieron a los nuevos médicos la estricta observancia de este método. Parece que en el hospital hubo varios documentos originales del doctor Francisco Jiménez Guillén sobre "pareceres y recados... en aprouaçión del método de la cura por la uía particular", que fueron encuadernados y guardados en el archivo de la institución para su consulta por orden de

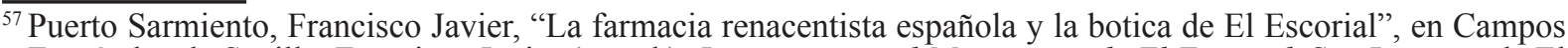
y Fernández de Sevilla, Francisco Javier (coord.), La ciencia en el Monasterio de El Escorial, San Lorenzo de El Escorial, Instituto escurialense de investigaciones históricas y artísticas, 1993, p. 90.

${ }^{58}$ Rabí Chara, Miguel, "La primera botica de los hospitales de la ciudad de Lima en el siglo XVI", en Asclepio, 52 (2010), p. 275, DOI «https://doi.org/10.3989/asclepio.2000.v52.i1.200».

${ }^{59}$ Sobre el utillaje y los repertorios de farmacopea que hubo en la botica de este hospital véase López Díaz, Teresa María et al., "Utillaje y libros de la botica del Hospital de las Cinco Llagas de Sevilla (1542-1744)", en Archivo Hispalense, 246 (1998), pp. 101-122.

${ }^{60}$ ADPSE, Hospital del Amor de Dios, lib. 2, f. 23v, 26r y 27r.

${ }^{61}$ En el inventario hecho el 13 de agosto de 1599 se recogió la existencia de "un Mensue de botica, nuevo, de impresión nueva; un Laguna sobre Dioscórides; otro libro Luminare Mayus" (ADPSE, Hospital de San Hermenegildo, leg. 2, Sf.).
} 
los patronos el 13 de octubre de 1613. Desgraciadamente, esta documentación no ha llegado a conservarse, desconociéndose cualquier particular sobre la misma ${ }^{62}$.

Junto a los libros de consulta, el principal instrumento de trabajo para el boticario fue el libro de botica, en el que se detallaban los medicamentos que el médico había ordenado durante la visita. En Sevilla, el libro adoptó un orden cronológico, con inclusión del número de la cama del paciente y variadas anotaciones de carácter económico, ya que eran objeto de pesquisa por parte de los administradores.

Uno de los hospitales que mejor recogía el procedimiento jurídico sobre este asunto fue el del Espíritu Santo, en cuyas constituciones de 1591, se dejó todo pormenorizado. En los estatutos se indicó que el boticario tuviese un libro blanco destinado a la redacción de las recetas dictadas por el médico durante la visita matutina:

\footnotetext{
A de tener un libro blanco en que, cada día, asiente las mediçinas que se ordenaren a los enfermos, poniendo en el nombre de cada vno el número de las camas, y a de lleuar las mediçinas que el médico y cirujano hordenaren, cada vna en su uasso cubierto con papel y escripto en él el número de la cama del enfermo porque no se truequen y se den vnas por otras. ${ }^{63}$
}

Cada tarde el administrador iba a la botica para asegurarse de que se había asentado todo lo ordenado por el médico, sirviendo este libro para corroborar los gastos en medicina. La fiscalización de los libros y cuadernillos de botica fue constante; así, en el libro más antiguo conservado en el Hospital del Amor de Dios, que comienza el 17 de octubre de 1800, son continuas las rúbricas de los claveros del hospital, apareciendo marginalmente las del boticario, que pagaba de su propio peculio los productos hasta recibir el libramiento por parte de los oficiales del hospital ${ }^{64}$ [fig. 4].

A pesar de que su puesta por escrito correspondía al boticario, el libro podía ser examinado por los médicos para verificar que el contenido recogido se correspondía a lo ordenado por él, como se dictaminó en el Hospital General de Madrid, en cuyas constituciones se exigía que los médicos habían de «reconocer y examinar estas libretas», procediéndose a la firma de cada asiento una vez examinado su contenido ${ }^{65}$.

Ya, en el siglo XIX, se experimentaron importantes cambios en los libros de botica y, aunque seguían teniendo una finalidad fiscalizadora para la institución, los preparados del farmacéutico aparecen rubricados por este y por el médico, como ordenante de su dispensación. Del mismo modo, la receta se introdujo como documento indispensable para la preparación de fármacos, siendo expedidas por los médicos y debiendo entregarse en la botica, por lo que el sistema de visita, como tal, se modificó sustancialmente.

\footnotetext{
${ }^{62}$ ADPSE, Hospital de San Hermenegildo, lib. 1 A, f. $155 \mathrm{r}$.

${ }^{63}$ ADPSE, Hospital del Espíritu Santo, lib. 1 A, f. $12 \mathrm{v}$.

${ }^{64}$ ADPSE, Hospital del Amor de Dios, leg. 107.

${ }^{65}$ Constituciones y ordenanzas para el gobierno de los reales hospitales General, y de la Passión de Madrid, aprobadas por el rey nuestro señor señor don Carlos Tercero. Madrid, 1760, p. 53.
} 
Figura 4. Libro de botica del Hospital del Amor de Dios, 1800.

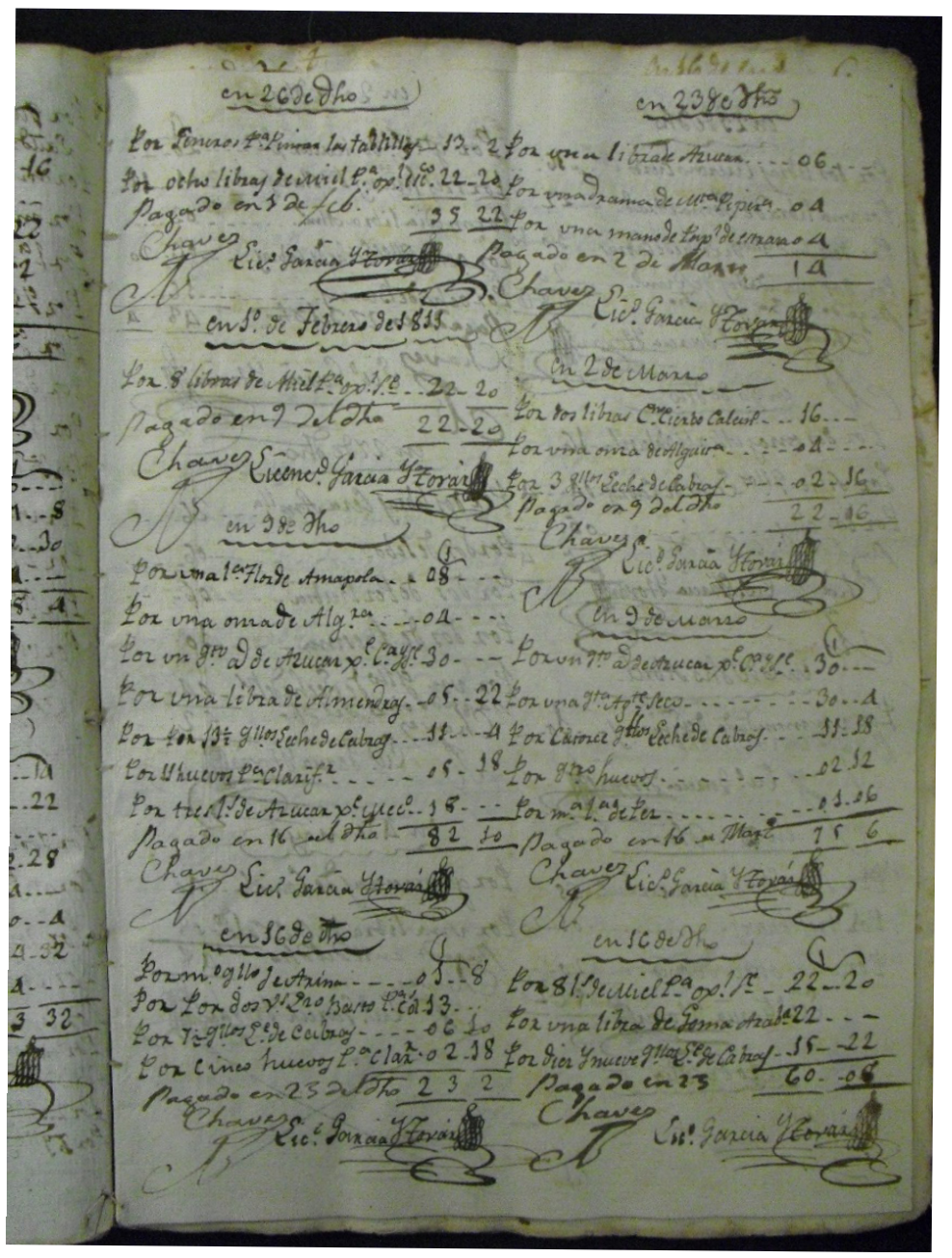

Fuente: ADPSE, Hospital del Amor de Dios, leg. 107.

La receta o formula seu praescriptio, definida como la consignación de uno o muchos remedios bajo determinada forma que dirige el médico al boticario, adoptó una estructura similar a la recogida en el Compendio de materia médica de $1809^{66}$. Su uso se extendió en la hospitalidad sevillana, conservándose un buen número de ellas en el Hospital de San Lázaro, constituyendo los únicos documentos de carácter sanitario de esta especie en este antiguo hospital ${ }^{67}$ [fig. 5].

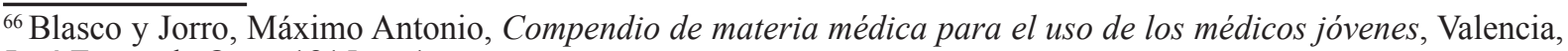
José Ferrer de Orga, 1815, p. 1

${ }^{67}$ ADPSE, Hospital de San Lázaro, leg. 50.
} 
Figura 5. Receta del Hospital de San Lázaro, (ca. 1810).

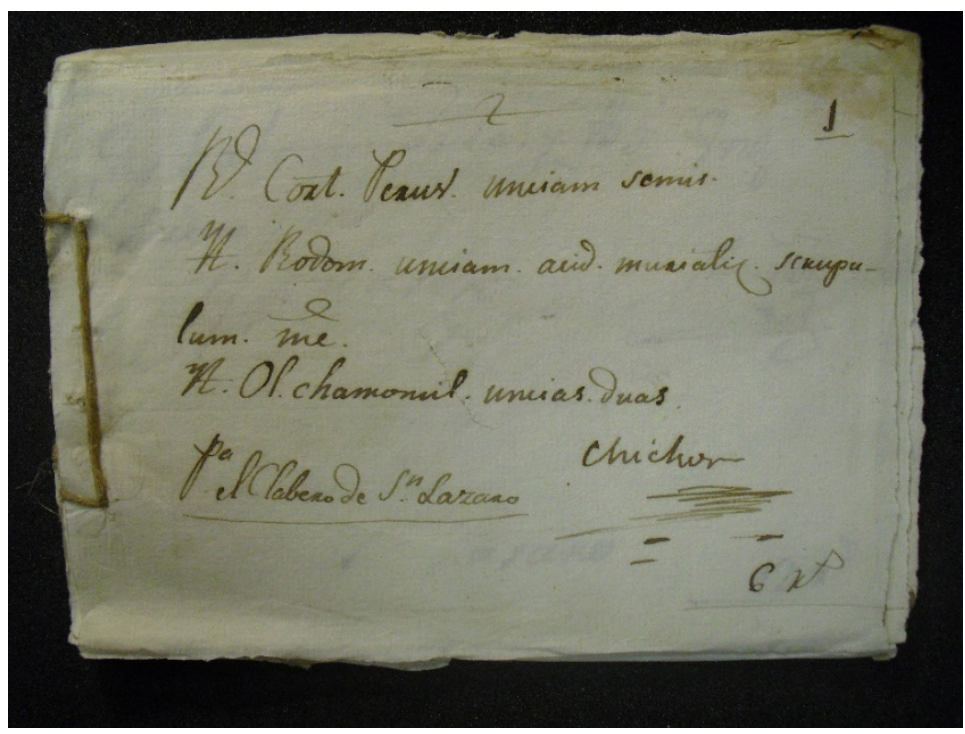

Fuente: ADPSE, Hospital de San Lázaro, leg. 50.

\section{Conclusiones}

Durante el Antiguo Régimen afloraron diferentes procedimientos de ingreso en la hospitalidad sevillana que variaban según las características intrínsecas de cada establecimiento y la naturaleza de las enfermedades y dolencias que se trataban. Como instrumento de control fiscal, y orientado a la administración del centro y los enfermos, se empezaron a utilizar libros en los que se registraron las entradas y salidas de los dolientes, constituyendo una de las series documentales más importantes de los fondos de beneficencia.

Los asientos y la estructura interna de los libros respondieron a las necesidades particulares de cada uno de los hospitales, registrándose los datos esenciales de los pacientes con alguna información puntual de carácter sanitario.

Junto al ingreso, la visita médica fue el eje principal y vertebrador de la asistencia. El médico era acompañado por el personal sanitario y asistencial mientras iba dictando los remedios que debían aplicarse al paciente. Uno de los libros resultantes de la visita fue el de botica, en el que se consignaban los compuestos de forma particular y siguiendo un orden cronológico a modo de dietario, y estructurándose en asientos numerados que correspondían a las camas de los pacientes. 
La receta, como documento expedido por el médico, no hizo su aparición en la hospitalidad sevillana hasta el siglo XIX, ya que la prescripción médica era apuntada anteriormente por el boticario en su libro, revistiendo las formalidades y la estructura que se seguían en el momento.

En esta misma centuria, dio comienzo un proceso de transformación interna de la hospitalidad que afectó a los libros de administración de enfermos, modificándose su estructura, pero persistiendo sus funcionalidades. 